\title{
Aplicação do método resistivo-capacitivo para investigação de uma área contaminada por creosoto
}

\author{
Carmona, E. A. F. (IAG-USP), Barbosa, A. M. (IPT), Ustra, A. (IAG-USP), Elis, V. (IAG-USP), Mendonça, C. (IAG-USP)
}

Copyright 2018, SBGf - Sociedade Brasileira de Geofísica

Este texto foi preparado para a apresentação no VIII Simpósio Brasileiro de Geofísica, Salinópolis, 18 a 20 de setembro de 2018. Seu conteúdo foi revisado pelo Comitê Técnico do VIII SimBGf, mas não necessariamente representa a opinião da SBGf ou de seus associados. É proibida a reprodução total ou parcial deste material para propósitos comerciais sem prévia autorização da SBGf.

\section{Resumo}

O uso da geofísica já e tradicional na área ambiental para estudo e caracterização de áreas contaminadas, uma vez que, para este fim, existe uma grande variedade de métodos com excelência de resultados, relativamente não invasivos e de baixos custos de aplicação. Este trabalho foi realizado com o intuito de investigar uma área contaminada por creosoto (derivado de hidrocarboneto) utilizando o método resistivo-capacitivo. Os resultados permitiram identificar zonas de alta resistividade, que foram atribuídas a presença do contaminante. $\mathrm{O}$ método empregado se mostrou promissor para a identificação e monitoramento desse contaminante em subsuperfície.

\section{Introdução}

A geofísica ambiental hoje já é muito difundida mundialmente, devido a sua capacidade de detecção e mapeamento de contaminantes em subsuperfície. Dentre as diversas áreas da geofísica aplicada, a ambiental é uma que vem ganhando destaque nos últimos anos, tanto no contexto acadêmico, quanto no corporativo. Existem atualmente uma grande variedade de métodos e arranjos que podem ser empregados de acordo com necessidades especificas.

A área de estudo investigada nesse trabalho abrigou atividades de tratamento químico de madeiras entre as décadas de 70 e 90 . O terreno se localiza na região de várzea do Rio Pinheiros (São Paulo-SP) e possui feições geológicas de depósitos quaternários, compostos por camadas de argila, areia e cascalho, com granodecrescência ascendente, sobrepostos por uma camada de aterro argiloso de $\sim 2 \mathrm{~m}$ de espessura. Sob os sedimentos aluvionares encontram-se os depósitos terciários da Bacia de São Paulo. (FREITAS et al., 2015) Em 2011, o Instituto de Pesquisas Tecnológicas (IPT) iniciou uma investigação na área, que confirmou a contaminação do solo por creosoto, utilizado no tratamento de madeiras. Um levantamento de eletrorresistividade realizado no fim de 2013 identificou zonas de alta resistividade próximas à antiga fonte da contaminação. (FREITAS et al., 2015)

O objetivo desse estudo é utilizar o método resistivocapacitivo para a investigação dessa área, onde a não apenas a contaminação está confirmada, mas existem poços de monitoramento e dados sobre a ocorrência do produto residual e potencial.

\section{Metodologia}

A eletrorresistividade capacitiva é uma metodologia de obtenção da resistividade elétrica que não requer acoplamento galvânico dos eletrodos (cravação de eletrodos) com a superfície do terreno. Com isso, uma grande vantagem dessa metodologia é que ela permite uma contínua aquisição de dados, possibilitando a investigação de grandes áreas com rápida operação de campo. De acordo com KURAS (2002), a Resistividade Capacitiva tem um modo único de operação, com as seguintes características:

1. Um dipolo elétrico oscilante não ligado à superfície é usado como fonte controlada para criar um fluxo de corrente elétrico no terreno;

2. As frequências empregadas são moderadas, na faixa de áudio $(16,5 \mathrm{KHz})$;

3. As medições operam em um modo quasi-estático sob condições de baixo número de indução;

4. O mecanismo de acoplamento entre o sensor e a superfície do terreno é por capacitância; ou seja, o acoplamento é principalmente fornecido por um campo elétrico e os efeitos indutivos são negligenciáveis. Os sensores são referidos como eletrodos capacitivos;

5. Sob condições quasi-estáticas, nas quais o efeito indutivo pode ser desconsiderado, as medidas de resistividade capacitiva são essencialmente equivalentes àquelas adquiridas pelo método de caminhamento elétrico convencional (com cravação de eletrodos no solo). Sendo assim, as resistividades obtidas podem ser trabalhadas segundo as metodologias convencionais de interpretação (CAVENAGHI, 2017).

A figura 1 mostra uma representação esquemática do modelo conceitual utilizado no método resistivocapacitivo. Os eletrodos do dipolo são cabos coaxiais, sendo que a blindagem de cobre do cabo atua como uma placa do capacitor, na qual é estabelecida uma corrente alternada com frequência de $16,5 \mathrm{kHz}$. O terreno atua como a outra placa. $O$ isolante atua como um dielétrico do capacitor. Dessa forma, o sinal de corrente alternada passa do cabo dipolar para o terreno via capacitância. $O$ sinal de corrente contínua é bloqueado. (CAVENAGHI, 2017).

Exceto pelo não acoplamento com o solo, o funcionamento de um levantamento de resistividade capacitiva é bastante semelhante ao de um levantamento convencional, necessitando de um par de "eletrodos" transmissores e pares de "eletrodos" receptores (no caso, os eletrodos são substituídos por cabos que funcionam como antenas) (CAVENAGHI, 2017). A figura 2 ilustra a medição de potencial elétrico com a eletrorresistividade tradicional e com o método resistivo-capacitivo. 
Os sistemas de aquisição para a resistividade capacitiva são formados (em uma configuração básica) por um transmissor, um conjunto de receptores e o registrador dos dados. Sua fundamental diferença com relação ao sistema de caminhamento elétrico da eletrorresistividade é o não acoplamento físico de eletrodos com o solo, que neste caso, se dá por capacitância elétrica (CAVENAGHI, 2017).

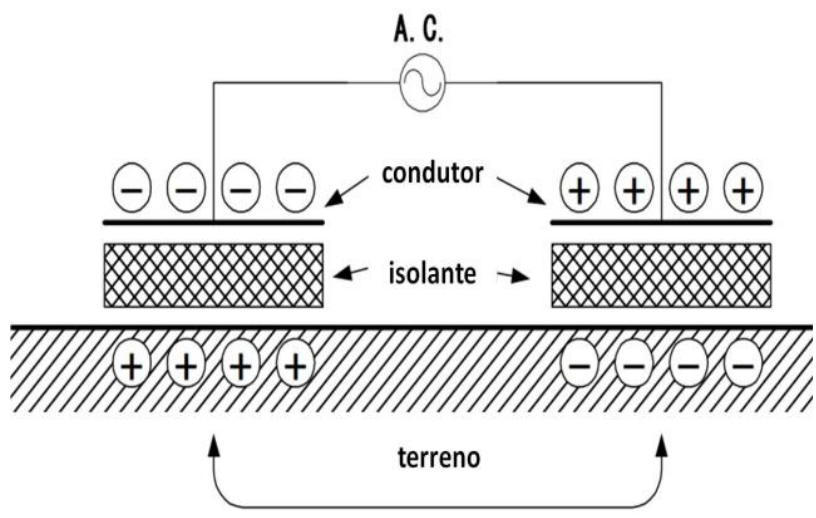

Figura 1 - Representação esquemática do acoplamento capacitivo utilizado no método resistivo-capacitivo (YAMASHITA et al., 2004)

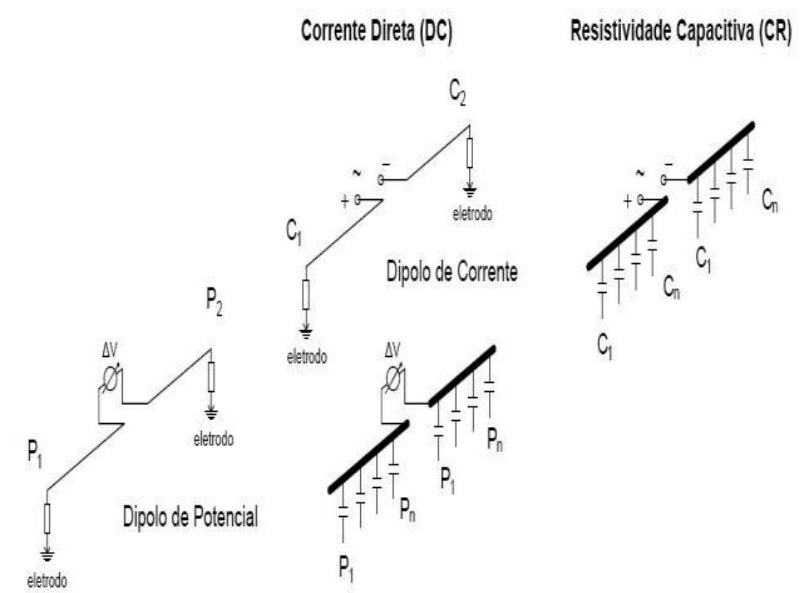

Figura 2 - Comparação entre os modos de medição de potencial elétrico $(\Delta V)$ com o método eletrorresistividade (esquerda) e resistivo-capacitivo (direita), ambos em arranjo dipolo-dipolo. A letra $\mathrm{P}$ indica pontos de medição de potencial, enquanto a letra $C$ indica pontos de injeção de corrente elétrica (CAVENAGHI, 2017).

Ainda de acordo com CAVENAGHI (2017), o regime quasi-estático é válido para a maioria das frequências eletromagnéticas utilizadas e assume que 0 deslocamento de corrente pode ser efetivamente ignorado quando comparado com a condução de corrente. A intensidade do campo magnético $(\nabla \mathrm{xH})$ é descrita como a soma entre a densidade de corrente $(\mathrm{J})$ e o deslocamento de corrente no tempo ( $\partial \mathrm{D} / \partial \mathrm{t})$ $\nabla \times \mathrm{H}=\mathrm{J}+\partial \mathrm{D} / \partial \mathrm{t}(1)$

Sob condições de espaço livre, onde a frequência do campo eletromagnético possui um comprimento de onda consideravelmente maior do que o espaçamento entre o transmissor-receptor, o campo magnético varia tão lentamente que a diferença relativa em resposta ao sinal com o tempo é insignificante e, por isso:

$\mathrm{J}>>\partial \mathrm{D} / \partial \mathrm{t}(2)$

Devido a este fato, $\partial \mathrm{D} / \partial \mathrm{t}$ pode ser considerado negligenciável e a intensidade do campo magnético irá depender diretamente e somente da densidade de corrente (ADAMS, 2008), onde:

$\nabla \times \mathrm{H}=\mathrm{J}(3)$

Com relação ao número de indução $(\mathrm{B})$, este descreve a natureza da indução eletromagnética em função da geometria do arranjo e das propriedades elétricas. B é definido como a razão entre um comprimento "s" e o skin depth calculado para o terreno (MCNEIL, 1980):

$$
B=\frac{s}{\delta}=s \sqrt{\frac{\varpi \mu_{0} \sigma}{2}}
$$

Onde,

$\delta=$ Skin depth

$\omega=$ Frequência angular

$\mu 0=$ Permeabilidade Magnética

$\sigma=$ Condutividade elétrica

O comprimento "s" pode ser dado como a distância entre o centro do dipolo transmissor e o centro do dipolo receptor, equivalente à distância entre a bobina transmissora e a bobina receptora no formalismo eletromagnético. (CAVENAGHI, 2017).

O equipamento utilizado para a aquisição dos dados foi o OhmMapper, da GEOMETRICS, mostrado na figura 3. Os receptores representados na imagem estão ligados entre si através de cabos dipolares, e o transmissor é ligado ao sistema de recepção por meio de uma corda não condutora. Todo o conjunto é rebocado por um operador ou veículo. Nesse sistema, os cabos dipolares equivalem aos eletrodos no arranjo convencional (CAVENAGHI, 2017).

A figura 4 mostra 3 linhas do levantamento geoelétrico: IPT1, "background"; IPT2, onde foi observado o contaminante na fase livre; IPT3, onde foi o contaminante foi detectado na fase residual. Cada uma das três linhas foi repetida três vezes, com separação de $2,5 \mathrm{~m}, 5 \mathrm{~m}$ e $10 \mathrm{~m}$, entre o centro do dipolo transmissor e o centro do dipolo receptor.

Os dados de resistividade aparente obtidos foram interpretados com o software RES2DINV para gerar as sessões de resistividade (Geotomo Software, 2003). 


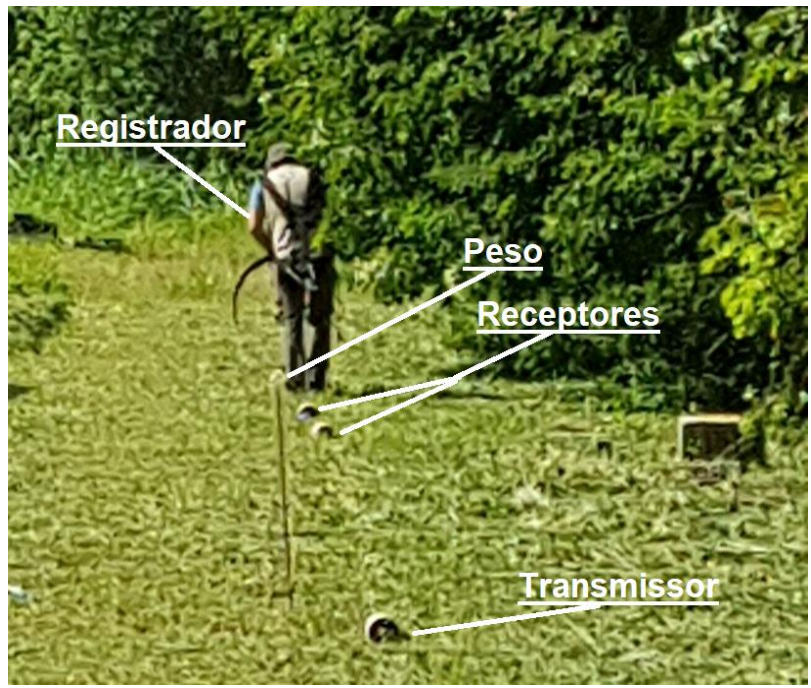

Figura 3 - OhmMapper e seus componentes sendo utilizado para aquisição dos dados

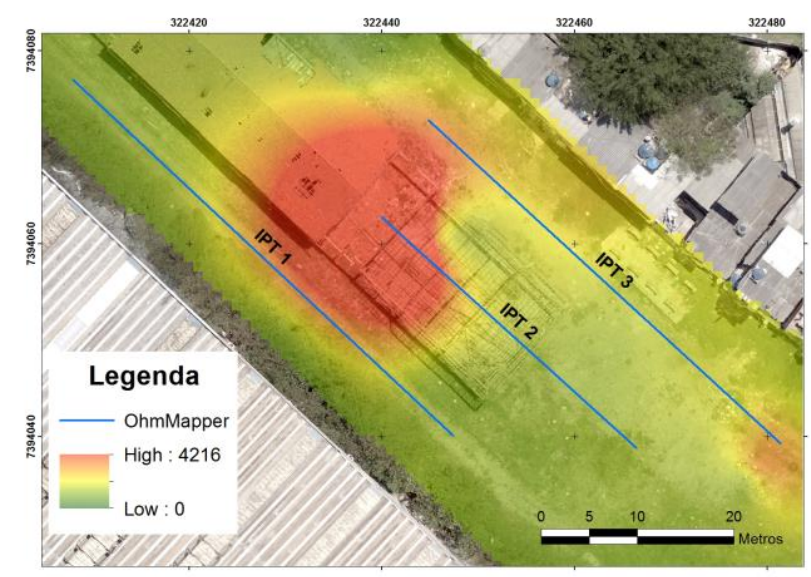

Figura 4 - Foto aérea da área de estudo com mapa de contorno da concentração de TPH (Hidrocarbonetos Totais de Petróleo), linhas de resistividade capacitiva em azul

\section{Resultados e Discussão}

As sessões de resistividade das três linhas são apresentadas pelas figuras 5,6 e 7 . Os parâmetros de aquisição de dados permitiram alcançar uma profundidade de investigação em torno de $4 \mathrm{~m}$, profundidade que se encontra inteiramente na zona não saturada.

O modelo de resistividade da linha IPT 1 (figura 5), é considerada como uma linha de referência, por passar por poços de monitoramento onde o contaminante não foi detectado. Ainda assim, essa linha intercepta parte da pluma de naftaleno detectada pelos dados de poços. Baseado nas feições observadas na figura 5 , os valores de resistividade entre 50 e $150 \mathrm{ohm}$.m foram interpretado como variações naturais do meio geológico local, ou seja, a assinatura geoelétrica do background.

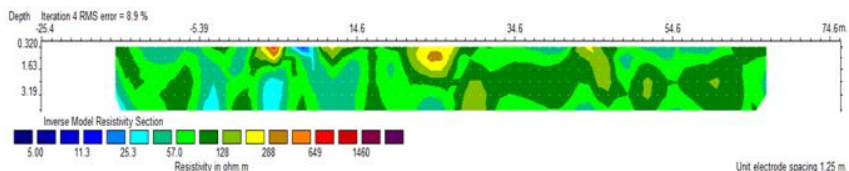

Figura 5-Sessão de resistividade da linha IPT 1

O modelo de resistividade da linha IPT 2 (figura 6), observa-se duas principais feições resistivas, com valores de resistividade acima de $600 \mathrm{ohm}$.m. A primeira ocorre em aproximadamente $0 \mathrm{~m}$ ao longo da linha, a aproximadamente $3,2 \mathrm{~m}$ de profundidade, e a segunda em aproximadamente $35 \mathrm{~m}$ ao longo da linha, próxima a superfície. Essas zonas de alta resistividade foram interpretadas como a presença do contaminante, que foi identificado nessa região na fase livre. Especula-se que as zonas de resistividade inferiores a $20 \mathrm{ohm} . \mathrm{m}$, que correm adjacentes as zonas de alta resistividade sejam regiões onde o contaminante está sendo degradado. De fato, espera-se que a biodegradação resulte no aumento da condutividade do meio, como resultado do aumento de sólidos totais dissolvidos decorrentes da dissolução mineral provocada pela produção de ácidos orgânicos e carbônicos subprodutos da atividade metabólica dos micro-organismos (Atekwana e Atekwana, 2010). Entretanto, análise adicionais são necessárias para comprovar essa hipótese.

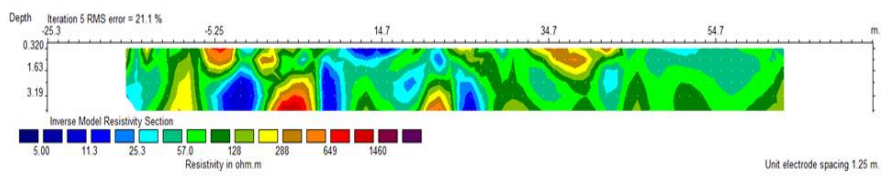

Figura 6 - Sessão de resistividade da linha IPT 2

O modelo de resistividade da linha IPT 3 (figura 7) mostra uma zona com valores de resistividade acima de 600 ohm.m, desde aproximadamente $24 \mathrm{~m}$ até $50 \mathrm{~m}$ ao longo da linha. Essa zona resistiva foi interpretada como a presença do contaminante, que foi detectado nessa região, na fase residual. Novamente, condutividade abaixo de 20 ohm.m são observadas adjacentes as zonas resistivas, sugerindo serem referentes a biodegradação.

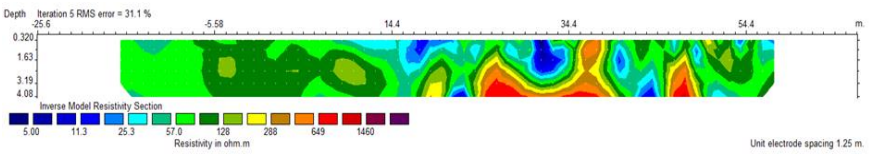

Figura 7 - Sessão de resistividade da linha IPT 3

\section{Conclusões}

Uma área contaminada por creosoto foi investigada pelo método resistivo-capacitivo. O método forneceu dados que permitiram identificar a presença do contaminante, por valores de aumento de resistividade. Os resultados apresentados fazem parte de um projeto de investigação 
que tem o objetivo de delinear a área afetada para o seu posterior monitoramento.

\section{Agradecimentos}

Agradecemos ao Instituto de Pesquisas Tecnológicas pelo acesso a área e auxílio na realização dos ensaios de campo. Agradecemos também os técnicos do IAG/USP Ernande Santos e Marcelo Stangari.

\section{Referências}

ADAMS, A. H. 2008. Capacitive Array Resistivity with an Inductive Source. Tese de doutorado, RMIT University, Melborne, Austrália, 243p.

ATEKWANA, E. A., ATEKWANA, E. A.

2010. Geophysical signatures of microbial activity at hydrocarbon contaminated sites: A review. Surv. Geophys, 31(2):247-283

CAVENAGHI, V. L. S., 2017. Caracterização geoelétrica de alvos rasos no Sítio Controlado de Geofísica Rasa-II IAG/USP através do uso de resistividade capacitiva. Dissertacao (Mestrado em Geofisica) Universidade de São Paulo, 2017. p. 6-44

FREITAS, L. G. de, GANDOLFO, O. C. B., YOSHIKAWA, N. K., BARBOSA, A. M., LEITE, D. C., 2005. Utilização da Sonda MIP para caracterização estratigráfica de uma área contaminada. IV Congresso Internacional de Meio Ambiente Subterrâneo

GEOMETRICS, INC. 2001. OhmMapper TR1 29005-01 REV. F - Operation Manual, 147p.

GEOTOMO SOFTWARE. RES2DINV, version 3.53, Rapid 2D resistivity \& IP inversion using the least-square method - Geoelectrical Imaging 2-D \& 3-D, Geotomo Software, Penang, Malaysia. 129 p. 2003.

KURAS, O., 2002. The capacitive resistivity technique for electrical imaging of the shallow subsurface: Ph.D. thesis, University of Nottingham. 286 p.

MCNEILL J.D. 1980. Eletromagnetic Terrain Conductivity Measurement at Low Induction Numbers. Technical Note TN-6. Geonics Limited.

YAMASHITA, Y., GROOM, D., INAZAKI, T., HAYASHI, K., 2004. Rapid near surface resistivity survey using the capacitively-coupled resistivity system: OhmMapper,
Proceeding of 7th SEGJ International Symposium, p. 292295. 